\title{
Determination of Trace Amounts of Cobalt(II) by Flow Injection-Solid Phase Spectrometry (FI-SPS) with 5-Br-PADAB
}

\author{
Shiro MatsuoKa, ${ }^{* \dagger}$ Nobutoshi ShIOTA, ${ }^{* *}$ and Kazuhisa Yoshimura** \\ *Department of Environmental Science, Faculty of Science, Niigata University, Ikarashi, Niigata 950-2181, Japan \\ **Department of Chemistry, Faculty of Sciences, Kyushu University, Ropponmatsu 4-2-1, \\ Chuo-ku, Fukuoka 810-8560, Japan
}

\begin{abstract}
Flow injection-solid phase spectrometry (FI-SPS) has been applied to the determination of cobalt(II) in water samples. The complex formed between cobalt and 5-Br-PADAB was on-line protonated and concentrated on an AG 50W-X2 cation-exchanger in a flow-through cell. The increase in absorbance caused by the accumulation of the complex in the resin was continuously measured. The interference by copper could be effectively eliminated by using EDDP as a masking agent. The detection limit was $40 \mathrm{ng} \mathrm{dm}{ }^{-3}$ with a $4.0 \mathrm{~cm}^{3}$ sample solution.
\end{abstract}

(Received September 17, 2005; Accepted November 21, 2005)

\section{Introduction}

Cobalt is of considerable interest in many fields, such as geochemistry and environmental chemistry, and especially in the field of biochemistry because it is concerned with human bio-chemical metabolism. ${ }^{1}$ However, since it occurs at very low levels in natural waters or in living organisms, these very low concentrations of cobalt have made it difficult to understand its chemistry.

Spectrophotometry has been most frequently used for the determination of cobalt in solution because of its high costperformance, improvements in instrumental design and the development of more sensitive and selective reagents. However, it is difficult to directly apply spectrophotometry to the determination of trace elements present at $\mu \mathrm{g} \mathrm{dm}{ }^{-3}$ or less without using some troublesome preconcentration procedures. ${ }^{2}$ Although many determination methods, such as AAS, ${ }^{3}$ ICPAES, ${ }^{4}$ ICP-MS ${ }^{5}$ and stripping voltammetry, ${ }^{6}$ have also been applied to the determination of trace cobalt in various sample solutions, each of these methods has its advantages (due to high sensitivity) and disadvantages (due to troublesome determination procedures or expensive apparatus).

It has been reported that solid phase spectrophotometry (SPS), based on direct measurements of the degree of light-absorption or the emission light intensity by a solid phase in which a target chemical component is concentrated, is very effective for the determination of trace elements in water samples. ${ }^{7,8}$ For the trace amount of cobalt analysis, the attenuance of the anionexchange gel adsorbed with the cobalt-Nitroso-R complex ${ }^{9}$ or an anion-exchange resin adsorbed with the cobalt complex of 4(2-pyrizilazo)resorcinol (PAR $)^{10}$ has been measured. In the case of these batch methods, more than $1 \mathrm{dm}^{3}$ of a sample solution was necessary in order to attain a sensitivity of about 1000times higher than that of the corresponding conventional solution methods. If the sample species can be concentrated in

\footnotetext{
† To whom correspondence should be addressed.

E-mail: matsuoka@env.sc.niigata-u.ac.jp
}

a very small volume of solid phase packed in a flow-through cell and the attenuance increase by the adsorbed species is determined directly in the solid-phase, large amounts of samples are no longer needed. Furthermore, this makes it possible to greatly simplify the determination procedures. For this purpose, we have endeavored to extend solid-phase spectrophotometry to flow analysis, and have employed it for the sensitive determination of some elements in water samples. Since this technique was proposed in 1987, ${ }^{11,12}$ about 20 FI-SPS's for trace-metal ion determination have been reported. ${ }^{13,14}$ In spite of using not so expensive equipment, this FI-SPS method has a high enough sensitivity to be directly applied to the analysis of very diluted sample components at low levels (sub- $\mu \mathrm{g} \mathrm{dm}^{-3}$ ) in solution.

It is known that some pyridylazo derivatives, such as PADAB (pyridylazodiaminobenzene), PADAP (pyridylazodiaminophenol) or PAMB (pyridylazodiaminobenzoic acid), form stable complexes with some transition metals, such as iron, cobalt, nickel and zinc, and their molar absorptivities are on the $10^{5}$ order. $^{15}$ In our preliminary experiments, it was confirmed that 2-(5-bromo-2-pyridylazo)-5-diethylaminophenol (5-Br-PADAB) is very useful for cobalt analysis using FI-SPS because it forms a stable complex with cobalt in an acidic medium, and this complex is strongly adsorbed on a cation-exchange resin. In this study, this useful reagent for cobalt analysis was applied to FI-SPS of trace amounts of cobalt at $\mu \mathrm{g} \mathrm{dm}^{-3}$ levels in various samples.

\section{Experimental}

\section{Chemicals}

All of the chemicals used were of analytical-reagent grade. Demineralized water prepared with a Milli-Q SP system (Millipore, MA, USA) was used throughout. The solutions, except for the coloring reagent solution, were filtered through a $0.22 \mu \mathrm{m}$ membrane filter paper (Millipore). Dissolved gases were expelled from the solution by means of an ultrasonic bath at $40^{\circ} \mathrm{C}$. 
The standard cobalt solution (1000 $\mathrm{mg} \mathrm{dm}^{-3}$ ) was supplied by Kishida (Osaka, Japan). A working solution $\left(50 \mu \mathrm{g} \mathrm{dm}^{-3}\right)$ containing $0.1 \mathrm{~mol} \mathrm{dm}^{-3}$ hydrochloric acid was prepared.

A MES buffer solution $\left(0.5 \mathrm{~mol} \mathrm{dm} \mathrm{dm}^{-3}, \mathrm{pH} 6.0\right)$ was prepared by dissolving $26.7 \mathrm{~g}$ of MES (2-( $N$-morpholino)ethanesulfonic acid, monohydrate, purchased from Dojin, Kumamoto, Japan) in $250 \mathrm{~cm}^{3}$ of water containing about $0.5 \%(\mathrm{v} / \mathrm{v})$ ammonia.

A masking agent solution for copper $\left(10^{-3} \mathrm{~mol} \mathrm{dm}{ }^{-3}\right.$ EDDP solution) was prepared by dissolving $0.14 \mathrm{~g}$ of EDDP (ethylenediamine- $N, N^{\prime}$-dipropionic acid, dihydrochloride, from Dojin) in $500 \mathrm{~cm}^{3}$ of water.

A sulfuric acid solution $\left(1 \mathrm{~mol} \mathrm{dm}^{-3}\right)$ was prepared by diluting $50 \mathrm{~cm}^{3}$ of concentrated sulfuric acid with water up to $1000 \mathrm{~cm}^{3}$.

A nonionic surfactant solution, $0.2 \%$ (v/v) Triton X-100 (polyethylene glycol mono[4-(1,1,3,3-teteramethylbutyl)phenyl]ether, purchased from Kishida) was prepared.

A coloring-agent solution, $10^{-4} \mathrm{~mol} \mathrm{dm}^{-3}$ of 5-Br-PADAB, purchased from Dojin, was prepared.

A buffer-masking solution (carrier solution for sample solution) was made by diluting a mixture of $200 \mathrm{~cm}^{3}$ of the buffer solution, $50 \mathrm{~cm}^{3}$ of the nonionic surfactant solution and $100 \mathrm{~cm}^{3}$ of the masking agent solution with water up to $1000 \mathrm{~cm}^{3}$.

A desorbing agent solution $\left(1 \mathrm{~mol} \mathrm{dm}^{-3}\right.$ sodium hydroxide solution) for the regeneration of the ion exchanger in the flowthrough cell was prepared by dissolving $40 \mathrm{~g}$ of sodium hydroxide into $1 \mathrm{dm}^{3}$ of water.

To directly measure the solid-phase light absorption, an AG 50W-X2 cation exchanger (100-200 mesh, Bio-Rad, CA, USA) in the $\mathrm{H}^{+}$form was packed into a flow-through cell.

\section{Apparatus}

Light measurements were made with a double-beam spectrophotometer (Model UVIDEC-320, Nippon Bunko, Tokyo, Japan). An internally mirrored tube was placed between the cell holder and the light detector window of the spectrophotometer in order to recover the transmitted light scattered by the solid layer in the cell. A perforated metal plate of attenuance 2 was inserted in a reference beam to balance the light intensities. ${ }^{11}$

The flow-through cell (GL Science, Tokyo, Japan) had a lightpath portion of $10-\mathrm{mm}$ in length and $1.5 \mathrm{~mm}$ in diameter (about $0.02 \mathrm{~cm}^{3}$ ), and was black, except for the light-path portion. The ion-exchanger beads were retained in the flow-through cell by placing a polypropylene filter tip at the end of the cell. The length of the solid particle layer in the light-path portion of the cell was no longer than $5 \mathrm{~mm}$ (about $0.02 \mathrm{~cm}^{3}$ ). ${ }^{11-13}$

\section{Flow diagram}

A schematic flow analysis diagram is shown in Fig. 1. The flow rates of both the buffer-masking solution and the sulfuric acid solution were $0.60 \mathrm{~cm}^{3} \mathrm{~min}^{-1}$, achieved by using a medium pressure pump (Model DM2M-1024, Sanuki, Tokyo, Japan). The tubes were made of poly(tetrafluoroethylene) (PTFE, $1 \mathrm{~mm}$ i.d.). The sample and the desorbing agent solution were introduced into the flow system through respective PTFE sixway rotary valves (Model MPV-6, GL Science) connected to PTFE tube loops of $4.0 \mathrm{~cm}^{3}$ and $2.0 \mathrm{~cm}^{3}$, respectively.

\section{Procedure for the determination of cobalt}

Natural water samples were immediately filtered through a $0.22 \mu \mathrm{m}$ membrane filter (Millipore) at sampling points. To $100 \mathrm{~cm}^{3}$ of a natural water sample, $1.0 \mathrm{~cm}^{3}$ of concentrated hydrochloric acid was added to prevent cobalt adsorption by the walls of the container.

For rock samples, $100 \mathrm{mg}$ of a powdered sample was

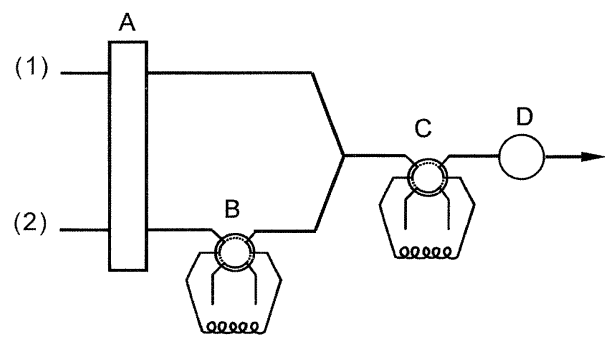

Fig. 1 Schematic diagram for FI-SPS. A, pump; B, six-way rotary valve for sample introduction; $\mathrm{C}$, six-way rotary valve for desorbing agent introduction; $\mathrm{D}$, ion exchanger packed detector in spectrophotometer (wavelength: $575 \mathrm{~nm}$ ). Carrier solution: (1) $1 \mathrm{~mol}$ $\mathrm{dm}^{-3} \mathrm{H}_{2} \mathrm{SO}_{4}$; (2) $0.1 \mathrm{~mol} \mathrm{dm}{ }^{-3} \mathrm{MES}, 10^{-4} \mathrm{~mol} \mathrm{dm}^{-3}$ EDDP, $0.01 \%$ (v/v) Triton X-100 (pH 6.0). Flow rate: (1), (2) $0.6 \mathrm{~cm}^{3} \mathrm{~min}^{-1}$.

decomposed by heating with a mixture of $1 \mathrm{~cm}^{3}$ of concentrated nitric acid and $0.7 \mathrm{~cm}^{3}$ of concentrated hydrofluoric acid in a PTFE digestion bomb (Sanplatec N-25, Tokyo, Japan). Then, the solution was evaporated and the dry residue was dissolved into a $100 \mathrm{~cm}^{3}$ of $0.1 \mathrm{~mol} \mathrm{dm} \mathrm{dm}^{-3}$ hydrochloric acid.

In a $20 \mathrm{~cm}^{3}$ volumetric flask, $4 \mathrm{~cm}^{3}$ of the MES solution, 0.3 $\mathrm{cm}^{3}$ of the coloring agent solution, $1 \mathrm{~cm}^{3}$ of the nonionic surfactant solution and $2 \mathrm{~cm}^{3}$ of the masking agent solution were added into a sample solution up to $10 \mathrm{~cm}^{3}$ containing 2 $100 \mathrm{ng}$ of cobalt, and then the content was diluted with water to $20 \mathrm{~cm}^{3}$. For complete color development, the solution was allowed to stand for $30 \mathrm{~min}$ before being introduced into the buffer-masking agent solution stream via a six-way rotary valve connected with a $4.0 \mathrm{~cm}^{3}$ PTFE tube loop. After the sample solution was mixed with the sulfuric acid solution stream, the complex between cobalt and 5-Br-PADAB was adsorbed and concentrated on the cation exchanger in the flow-through cell. The attenuance at $570 \mathrm{~nm}$ was measured continuously and recorded on a strip-chart recorder set at the 0.5 absorbance fullscale. When the attenuance increase became constant, the desorbing agent solution was introduced into the stream for regeneration of the ion exchanger in the flow-through cell.

\section{Results and Discussion}

Optimization of the cobalt-5-Br-PADAB complexation and its sorption on the resin

Shibata et al. have reported that PADAB and its derivatives form a brown complex with $\mathrm{Co}$ (II) in a slightly-acidic to weakly-alkaline medium, and that the resulting Co(III) complex changes into a very stable, pink-colored, highly protonated complex after the addition of a highly concentrated mineral acid. ${ }^{15}$

A complex system with a higher molar absorptivity and a higher distribution ratio $(D)$ between the solution phase and the solid phase is suitable for SPS, and therefore the $\mathrm{Co}(\mathrm{II})-5-\mathrm{Br}-$ PADAB complex system is useful for this method because its molar absorptivity at $570 \mathrm{~nm}$ is on the order of $10^{5} \mathrm{~mol}^{-1} \mathrm{dm}^{3}$ $\mathrm{cm}^{-1}$, and it is easily concentrated in the cation exchanger of polystyrene type (the $D$ value was greater than $10^{4}$ in an acidic medium); the total net charge of the complex is expected to be +3 under neutral conditions and +5 in $1 \mathrm{~mol} \mathrm{dm}^{-3}$ acid solutions. ${ }^{15}$ Figure 2 shows the absorption spectra of the free ligand and its cobalt complex in the resin phase. The absorption maximum wavelengths are almost the same as those in solution, and the good separation of these two spectra could easily be 


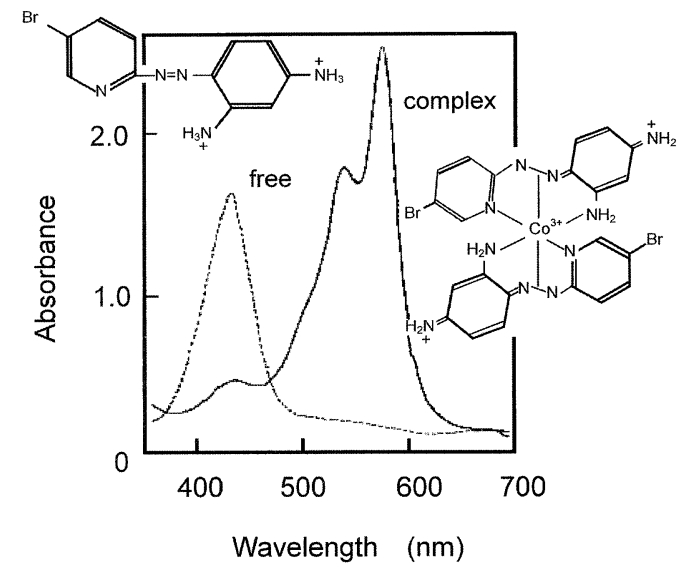

Fig. 2 Absorption spectra of 5-Br-PADAB and its cobalt complex in the ion exchanger phase. Resin, Bio-Rad AG 50W-X2 (100-200 mesh); solution, $0.5 \mathrm{~mol} \mathrm{dm}^{-3} \mathrm{H}_{2} \mathrm{SO}_{4}$.

applicable to cobalt analysis.

Although the Co(II)-5-Br-PADAB complex system was favorable in selectivity in an acidic medium, it had some drawbacks that should be overcome. One of them was the concentration of the reagent. Since the free 5-Br-PADAB was also distributed into the resin in the acidic medium, and had absorption at $570 \mathrm{~nm}$ to some extent, the 5-Br-PADAB concentration could not be increased in order to lower the reagent blank signal. The 5-Br-PADAB concentration for color development was finally fixed at $1.5 \times 10^{-6} \mathrm{~mol} \mathrm{dm}^{-3}$. However, because of such a low concentration of the coloring agent, the reaction was fairly slow. As shown in Fig. 3, it took about $30 \mathrm{~min}$ for complete color development at $\mathrm{pH} 6.0$ (the optimum $\mathrm{pH}$ for the complexation examined by a separate experiment was 6 to 9). The situation could not be improved even by heating the sample solution; therefore, the time for complexation was fixed for $30 \mathrm{~min}$ at room temperature.

Figure 4 shows the effect of the acid concentration on the adsorption of a protonated pink-colored complex to the cationexchange resin, examined by using the batch method. The higher concentration of $\mathrm{H}_{2} \mathrm{SO}_{4}$ made $D$ lower, which resulted in a decrease in sensitivity. The maximal adsorption of the complex was observed in a $\mathrm{H}_{2} \mathrm{SO}_{4}$ solution of 0.2 to $0.5 \mathrm{~mol}$ $\mathrm{dm}^{-3}$. As the selectivity of 5-Br-PADAB toward cobalt increased with an increase in the acid concentration, the $\mathrm{H}_{2} \mathrm{SO}_{4}$ concentration was adjusted to $0.5 \mathrm{~mol} \mathrm{dm}^{-3}$.

\section{Set-up of the flow analysis system}

The color-development profile due to the accumulation of the sample component in a solid phase can be simulated according to the plate theory. As already shown in a previous paper, almost all of the sample species was retained, even after the passage of at least $20 \mathrm{~cm}^{3}$ of a carrier solution in a system of $D$ higher than $10^{5} .{ }^{11-13}$ In the case of a low- $D$ system, in contrast, the sample species introduced was eluted from the solid phase in a fairly short time. The distribution ratio of the Co-PADAB complex, defined as

$$
D=\frac{\text { mol of cobalt sorbed } / \mathrm{dm}^{3} \text { of swollen ion exchanger }}{\mathrm{mol} \text { of cobalt } / \mathrm{dm}^{3} \text { of solution }}
$$

can be a measure of the cobalt retention in the flow-through cell. The $D$ value of the Co(III)-5-Br-PADAB complex was 2.0 $\times 10^{4}$, and the elution of the Co(III)-5-Br-PADAB complex was

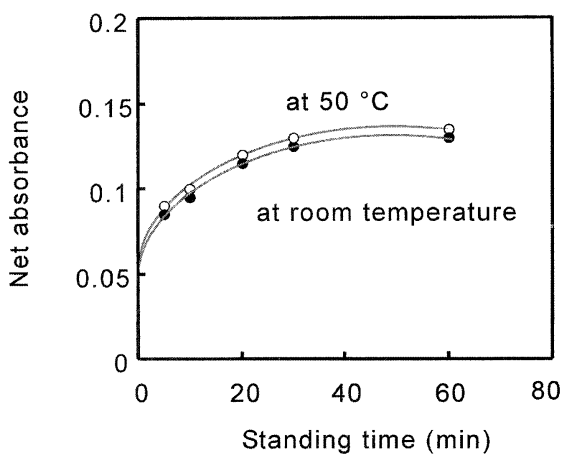

Fig. 3 Effects of the standing time on batchwise color development. Absorbance measurements, FI-SPS; sample, $1.0 \mu \mathrm{g}$ $\mathrm{dm}^{-3} \mathrm{Co}, 1.04 \mathrm{~cm}^{3} ; 1.0 \times 10^{-6} \mathrm{~mol} \mathrm{dm}{ }^{-3} 3$-Br-PADAB, $0.1 \mathrm{~mol} \mathrm{dm}^{-3}$ MES (pH 6.1), 0.01\% Triton X-100.

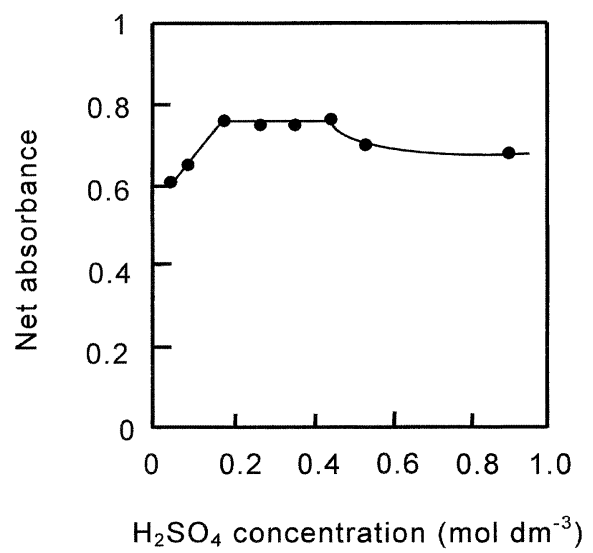

Fig. 4 Effect of the acid concentration on the adsorption of protonated pink-colored complex onto the cation-exchange resin. Absorbance measurements, SPS; resin, Bio-Rad AG 50W-X2 (100 200 mesh), $0.50 \mathrm{~g}$; solution, $2.5 \mu \mathrm{g} \mathrm{dm}^{-3} \mathrm{Co}, 1.0 \times 10^{-6} \mathrm{~mol} \mathrm{dm}^{-3} 5-$ Br-PADAB, $0.1 \mathrm{~mol} \mathrm{dm}^{-3}$ MES (pH 6.1), $0.01 \%$ Triton X-100; stirring time, $15 \mathrm{~min}$; cell length, $10 \mathrm{~mm}$.

not observed after the passage of $30 \mathrm{~cm}^{3}$ of the carrier solution. While the free 5-Br-PADAB also has a positive charge in an acidic medium, its $D$ value was $1.2 \times 10^{3}$, and it gradually eluted from the solid phase.

Some typical examples of color-development signals obtained with the proposed system are shown in Figs. 5(A-D). The calibration graph was obtained using the signal increase from the baseline, which corresponded to the amount of the colored chemical species adsorbed on the solid phase, and was expressed as

$$
\Delta A=0.0579 C+0.0820
$$

where $C$ is the sample concentration in $\mu \mathrm{g} \mathrm{dm}^{-3}$ when the sample volume introduced was $4.0 \mathrm{~cm}^{3}$.

In the case of the $\mathrm{Co}(\mathrm{III})-5-\mathrm{Br}-\mathrm{PADAB}$ complex, the diffusion into the solid phase seems to be very slow because of its bulkinesss. The linear velocity of the sample solution flowing through the solid particles in the flow-through cell was at about $1.1 \mathrm{~cm}^{-1}$, which may be faster than the diffusion rate. The adsorption of the colored species occurred only at the surface of solid particles, and this phenomenon resulted in a decrease of the adsorption sites that can be occupied by the complex. The 


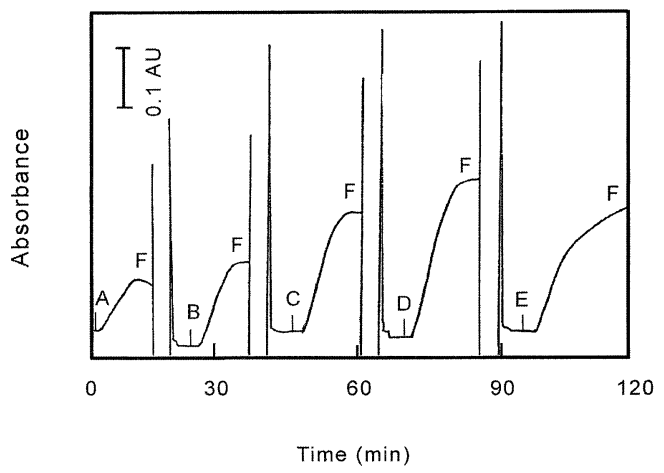

Fig. 5 Adsorption profile of the cobalt complex by FI-SPS. Sample volume: $4.0 \mathrm{~cm}^{3}$. A blank; B 1.0, C 2.0, D $3.0 \mu \mathrm{g} \mathrm{dm}^{-3} \mathrm{Co}$, E $3.0 \mu \mathrm{g} \mathrm{dm}^{-3}$ Co without Triton X-100; F desorbing agent.

resin amount packed in the cell, therefore, greatly affected the sensitivity: the greater was the amounts of the resin, the higher was the sensitivity. When the flow-through cell packed with the solid particles was used repeatedly, the slope of the calibration graph was almost constant. On the other hand, the fluctuation in the slope was observed to be from 0.05 to 0.2 , depending on the thickness of the solid particle layer in the flow-through cell. However, a straight calibration graph was obtained at least up to $3 \mu \mathrm{g} \mathrm{dm}^{-3}$ of cobalt, regardless of the resin amount.

As shown in Fig. 5(E), an unexpected color development signal was observed without using a nonionic surfactant. This was probably due to a fairly strong hydrophobic interaction between the target complex species and the surface moiety of the wall of the PTFE tube, which made not only the time required for each measurement longer, but also the reproducibility of the proposed system lower. This situation could be greatly improved by the addition of a nonionic surfactant, such as Triton X-100, both to a sample solution and the carrier solution. However, its concentration should not exceed the critical micellar concentration; otherwise, the sensitivity becomes lower.

\section{Effect of sample volume}

One of the features of the proposed method is a proportional increase of the sensitivity with increasing sample volume introduced into the flow system. At least up to $8 \mathrm{~cm}^{3}$, the sensitivity could be increased by increasing the sample volume. Although the signal corresponding to the reagent blank was also increased with the sample volume introduced, the slope for the Co-5-Br-PADAB complex was about 4-time greater than that for the reagent blank.

\section{Effect of foreign ions}

The effect of foreign ions on the determination of cobalt was examined, and the results were listed in Table $1 . \mathrm{A} \pm 5 \%$ error was considered to be acceptable. Most of the co-existing ions did not interfere even if their amounts were 1000-fold to that of cobalt. Only copper(II) gave a negative error (about -50\%) when it exceeded by 50 -fold the amount of cobalt. The interference from $\mathrm{Cu}$ (II) could be effectively eliminated by using EDDP as a masking agent; $1.0 \times 10^{-4} \mathrm{~mol} \mathrm{dm}^{-3}$ of EDDP in the sample solution was enough for this purpose.

In order to check the matrix effect, the cobalt content in a 500 $\mathrm{mg} \mathrm{dm}^{-3} \mathrm{Ca}(\mathrm{II})$ solution was also determined, but no effect could be found. It should be mentioned that the use of a phosphate buffer to adjust the $\mathrm{pH}$ of the sample solution around 7 was not suitable because the calcium in the sample solution
Table 1 Effects of foreign ions on the determination of cobalt

\begin{tabular}{cccc}
\hline $\begin{array}{c}\text { Foreign } \\
\text { ion }\end{array}$ & $\begin{array}{c}\text { Concentration/ } \\
\mathrm{mg} \mathrm{dm}^{-3}\end{array}$ & $\begin{array}{c}\text { Co found/ } \\
\mu \mathrm{g} \mathrm{dm}^{-3}\end{array}$ & Error, \% \\
\hline $\mathrm{Mg}^{2+}$ & 20 & 2.06 & +3 \\
& 50 & 1.83 & -8 \\
$\mathrm{Ca}^{2+}$ & 2.0 & 2.05 & +3 \\
& 50 & 1.94 & -3 \\
$\mathrm{Ni}^{2+}$ & 2.0 & 2.00 & 0 \\
& 20 & 0.52 & -74 \\
$\mathrm{Fe}^{2+}$ & 2.0 & 2.02 & +1 \\
& 10 & 1.81 & -9 \\
$\mathrm{Fe}^{3+}$ & 2.0 & 1.87 & -6 \\
& 20 & 1.78 & -11 \\
$\mathrm{Cu}^{2+}$ & 0.1 & 1.07 & -47 \\
& $0.0^{\mathrm{a}}$ & 1.91 & -5 \\
& $0.2^{\mathrm{a}}$ & 1.98 & -1 \\
$\mathrm{Zn}^{2+}$ & $2.0^{\mathrm{a}}$ & 1.86 & -7 \\
& 2.0 & 1.96 & -2 \\
& 10 & 1.85 & -8 \\
$\mathrm{~Pb}^{2+}$ & 20 & 1.68 & -16 \\
$\mathrm{Al}^{3+}$ & 2.0 & 1.93 & -4 \\
& 2.0 & 1.87 & -6 \\
& 20 & 1.78 & -11 \\
\hline
\end{tabular}

Sample: $2.00 \mu \mathrm{g} \mathrm{dm}{ }^{-3} \mathrm{Co}, 4.0 \mathrm{~cm}^{3}$.

a. In the presence of $1.0 \times 10^{-4} \mathrm{~mol} \mathrm{dm}^{-3}$ EDDP.

Table 2 Determination of cobalt in natural water samples

\begin{tabular}{lccc}
\hline \multicolumn{1}{c}{ Sample } & $\begin{array}{c}\text { Concentration factor } \\
\text { by evaporation }^{\mathrm{a}}\end{array}$ & $\begin{array}{c}\text { Cobalt concentration/ } \\
\mu \mathrm{g} \mathrm{dm}^{-3}\end{array}$ & $n$ \\
\hline Snow & 1 & 1.4 & 2 \\
River water $^{\mathrm{b}}$ & 5 & $0.11 \pm 0.02$ & 4 \\
Groundwater $^{\mathrm{c}}$ & & 0.12 & 2 \\
Akiyoshi-do Cave & 4 & $0.68 \pm 0.03$ & 4 \\
Nukumizu Spring & 4 & \\
\hline
\end{tabular}

a. $10 \mathrm{~cm}^{3}$ sample water were used after evaporation.

b. A tributary of the Tatara River in the Paleozoic amphibolite area, Kasuya, Fukuoka.

c. Karst groundwater in the Paleozoic limestone area, Yamaguchi.

was precipitated as $\mathrm{Ca}_{3}\left(\mathrm{PO}_{4}\right)_{2}$ if the calcium content was greater than $1000 \mathrm{mg} \mathrm{dm}^{-3}$. It is recommended to use the MES buffer to adjust the $\mathrm{pH}$ of sample solutions.

\section{Detection limit and precision}

The detection limit in terms of the amount of adsorbed cobalt on the cation-exchange resin in the cell was evaluated according to the IUPAC rulings. The calculated value from seven analyses of the blanks was $0.04 \mu \mathrm{g} \mathrm{dm}^{-3}$ for a $4.0 \mathrm{~cm}^{3}$ sample solution.

The precision was examined by using a $2.0 \mu \mathrm{g} \mathrm{dm}{ }^{-3}$ cobalt solution, and the net absorbance was $0.228 \pm 0.003(n=3)$. For three determinations, the RSD was $\pm 1.3 \%$.

In order to check the accuracy, the proposed method was applied to the analysis of a reference rock sample JB-1 (a basalt sample from the Geological Survey of Japan). The analytical result obtained was $37.1 \pm 2.1 \mu \mathrm{g} \mathrm{g}^{-1}(n=4)$, which was considered to agree with the certified value of $38.2 \mu \mathrm{g} \mathrm{g}^{-1}{ }^{16}$

The proposed method was also applied to various water samples. The results are listed in Table 2. There were no possible interferences by coexisting ions, and therefore water samples could be concentrated by evaporation before 
measurements if the cobalt contents in water samples were low. For a water sample from Nukumizu Spring, the standard addition method was applied. The recovery of the added cobalt was complete.

In the case of the Co(II)-5-Br-PADAB complex system, the deprotonated complexes, whose acid dissociation constant is 0.75 , have extremely high molar absorptivities. ${ }^{15}$ When the $\mathrm{Co}$ (II)-5-Br-PADAB complex system is applied to the conventional absorptiometry, some troublesome procedures are inevitable to make sample solutions and to measure the absorbances under strongly acidic conditions. This may be one of the reasons why this reagent has not been widely applied for Co analysis in spite of its high selectivity. In the case of the proposed flow method, however, the determination procedures are quite simple and about 100-time more sensitive than that of the corresponding conventional solution method that could be obtained under a $\mathrm{H}_{2} \mathrm{SO}_{4}$ concentration of $0.2-0.5 \mathrm{~mol} \mathrm{dm}^{-3}$.

\section{References}

1. E. J. Underwood, "Trace Elements in Human and Animal Nutrition", 4th ed., 1977, Academic Press, New York.

2. G. Yang, Z. Huang, Q. Hu, and J. Yin, Talanta, 2002, 58, 511 .
3. T. Minami, K. Atsumi, and J. Ueda, Anal. Sci., 2003, 19, 313.

4. K. S. Rao, T. Balaji, T. P. Rao, Y. Babu, and G. R. K. Naidu, Spectrochim. Acta, Part B, 2002, 57, 1333.

5. S. A. Bake and N. J. Miller-Ihli, Spectrochim. Acta, Part B, 2000, 55, 1823

6. B. Godlewska, J. Golimowski, A. Hulanicki, and C. M. G. Van den Berg, Analyst, 1995, 120, 143.

7. K. Yoshimura, H. Waki, and S. Ohashi, Talanta, 1976, 23, 449.

8. K. Yoshimura and H. Waki, Talanta, 1985, 32, 345.

9. T. Nakashima, K. Yoshimura, and H. Waki, Talanta, 1990 , 37, 735

10. M. L. F-De Cordova, A. Molina-Diaz, M. I. P-Reguera, and L. F. Capitan-Vallvey, Anal. Lett., 1992, 25, 1961.

11. K. Yoshimura, Anal. Chem., 1987, 59, 2922.

12. K. Yoshimura, Bunseki Kagaku, 1987, 36, 656.

13. K. Yoshimura and S. Matsuoka, Lab. Robotics Automation, 1993, 5, 231

14. M. Miro and W. Frenzel, Tre. Anal. Chem., 2004, 23, 11.

15. S. Shibata and S. Furukawa, Bunseki Kagaku, 1974, 23 , 1412.

16. N. Imai, S. Terashima, S. Itoh, and A. Ando, Geostandards Newsl., 1995, 19, 135. 